\title{
EFEITOS DO PENTOBARBITAL SóDICO SôBRE A ATIVIDADE ELÉTRICA CEREBRAL DO RATO COM LESÕES DA FORMAÇÃO RETICULAR MESENCEFÁLICA
}

\author{
Walter C. Pereira* \\ TANIA LEME Da Rocha** \\ CESAR TIMO-IARIa ***
}

Os fusos constituem manifestação eletrofisiológica cortical observada não só no homem, mas em todos os mamíferos utilizados em pesquisa neurofisiológica, sendo provável sua existência nos demais. Tanto no homem como nas outras espécies de mamíferos estudadas, ou fusos ocorrem apenas em algumas áreas do córtex cerebral e, embora seja de grande importância teórica saber se se projetam em áreas homólogas ou de conexões equivalentes nas diferentes espécies, não há estudos sistemáticos a êsse respeito. E obvio que, por induzirem fusos idênticos aos do sono natural, torna-se de sumo interêsse saber se os barbitúricos põem em ação os mesmos mecanismos responsáveis pelos fusos espontâneos. Não existe, contudo, até o presente, demonstração experimental definitiva da identidade de mecanismos em ambos os casos.

O objetivo dêste trabalho foi o de verificar de que maneira o barbitúrico interfere sôbre a configuração eletrofisiológica do cérebro isolado no rato, estudada em trabalho anterior ${ }^{12}$.

\section{MATERIAL E MÉTODOS}

Para êste estudo foram empregados 35 ratos albinos da raça Wistar em preparação aguda (24 com lesão bilateral e 11 com lesāo unilateral) e 18 em preparação crônica ou aguda com lesão prévia da formação reticular mesencefálica (13 e 5 animais, respectivamente). Pormenores sôbre a metodologia utilizada na preparação dos experimentos foram descritos em trabalho anterior ${ }^{12}$.

Nos animais em preparação aguda fizemos lesões progressivamente mais extensas da formação reticular mesencefálica, sendo o pentobarbital (Nembutal) injetado por via intravenosa em doses crescentes, tanto nos ratos com lesōes restritas como naqueles com destruições amplas. Nestes últimos, a fim de testar se havia integridade de parte da substância reticular, além de estímulos dolorosos intensos, aplicávamos pulsos de 5 a $10 \mathrm{~V}, 100 \mathrm{~Hz}$ e $0,1 \mathrm{~ms}$ abaixo da região correspondente à formação reticular destruida, mediante a introdução estereotáxica de um eletródio bipolar concêntrico de aço inoxidável. A ausência de reação de alerta cortical,

* Assistente da Clínica Neurológica; ** Assistente e *** Professor-Adjunto do Departamento de Fisiologia e Farmacologia do Instituto de Ciências Biomédicas da Universidade de São Paulo. Pesquisa financiada pela Fundação de Amparo à Pesquisa do Estado de São Paulo (FAPESP). 
ou seja, a dessincronização do eletrocorticograma (ECoG), assegurava-nos de que năo havia atividade do sistema reticular ativador ascendente. Nas preparações crônicas o pentobarbital foi administrado por via intraperitoneal, em doses sub-anestésicas, em algumas sessões durante a evolução da preparação. Desta maneira podíamos observar seu efeito sôbre a produção de fusos, comparando os resultados no animal em sono espontâneo ou vigília.

\section{R E S L T A DOS}

Os efeitos do pentobarbital sódico sôbre a atividade elétrica cortical do rato com lesão da formação reticular mesencefálica dependem de dois fatôres: dose da droga e extensão da lesão.

Para facilitar a exposição do assunto, descreveremos os efeitos do Nembutal em cada grupo de preparações em que foi empregado.

1. Em 4 preparações agudas com lesão bilateral restrita da formação reticular mesencefálica (região das comissuras posterior, habenular e dos colículos superiores) foram observados, no ECoG, potenciais de fuso esparsos e ondas lentas preponderantes. Em 2 dêstes animais a reação de alerta cortical à dor estava ausente e, nos outros, presente bilateralmente. Doses de 5 a $20 \mathrm{mg} / \mathrm{kg}$ de Nembutal, aplicado intravenosamente, provocaram o aparecimento de fusos bem organizados e com intermitência variável de 6 a 10 por minuto; com estas doses não foram observadas espiculas (fig. 1).

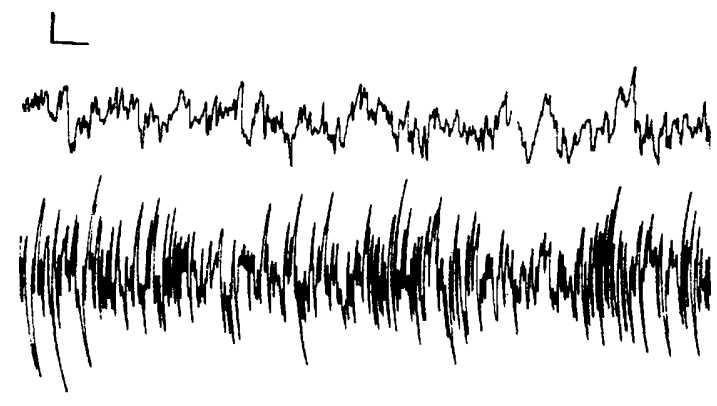

Fig. 1 - Efeito do Nembutal sôbre o ECoG de uma preparação aguda com lesão bilateral restrita da formação reticular mesencefálica. No traçado superior observa-se o aspecto antes da aplicacão da droga $e$, no inferior, a nitida sincronização vinte segundos depois da injeção de $10 \mathrm{mg} / \mathrm{kg}$ de Nembutal por via intravenosa. Calibração: $50 \mu \mathrm{V}$ e $1 \mathrm{~s}$.

2. Em 13 preparações agudas com lesão bilateral extensa (AP 1,9) o ECoG apresentava quantidade variável de fusos, geralmente bem organizados, associados a ondas lentas também variáveis de uma preparação para outra. Além disso, a intermitência dos fusos oscilava muito, podendo aumentar ou diminuir bruscamente de maneira acentuada. Em todos os animais dêste grupo a aplicação: de estímulos dolorosos intensos não provocava dessincronização do traçado eletrocorticográfico, demonstrando total interrupção do sistema reticular ativadr ascendente. $A$ aplicaৎão intravenosa de pentobarbital nas doses de 5 a $20 \mathrm{mg} / \mathrm{kg}$ de pêso determinava, 
em geral, após latência de 8 a 10 segundos, elevação brusca da periodicidade dos fusos, que comumente subia a niveis mais altos do que os até então alcançados (fig. 2).

Fig. 2- Elevação brusca da periodicidade dos fusos, em 4 preparações agudas com lesão bilateral extensa da formacão reticular mesencefálica, provocada pela injeção intravenosa de Nembutal. Notar que após a injeção a intermitência sobe a niveis até então não atingidos.

\section{№ DE FUSOS}
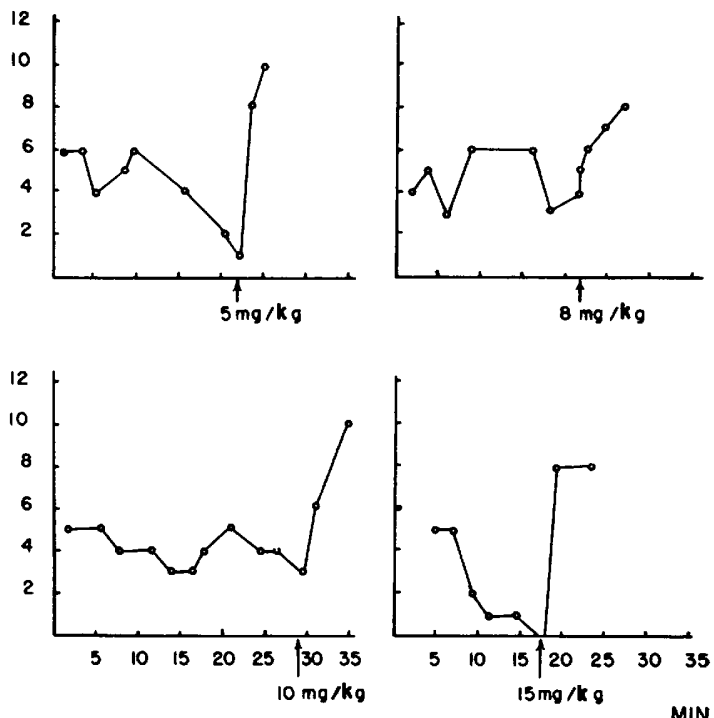

Além de elevarem quase sempre de maneira nitida a periodicidade dos fusos, as referidas doses de Nembutal os tornavam mais puros e regulares, raramente provocando o aparecimento de espículas nestas preparações.

3. Em 8 preparaçōes agudas com lesão bilateral mais extensa da formação reticular mesencefálica, atingindo também as porções ventrocaudais do diencéfalo (AP 1,9 e 2,9), o ECoG geralmente mostrava potenciais de fuso esparsos, grande predomínio de ondas lentas e, algumas vêzes, espiculas assincronas em ambos os hemisférios cerebrais. Nestes animais a reação de alerta à dor estava ausente e estímulos elétricos $(100 / \mathrm{s}, 0,1 \mathrm{~ms}$ e 5 a $10 \mathrm{~V})$, aplicados abaixo da formaçāo reticular destruída, não provocavam dessincronização do ECoG. A injeção intravenosa de 5 a $20 \mathrm{mg} / \mathrm{kg}$ de Nembutal produzia depressão intensa da atividade elétrica cortical, que se tornava, na maioria dos casos, práticamente inexistente por períodos mais ou menos longos de tempo. Tais períodos de inatividade elétrica cortical eram interrompidos, de vez em quáfido, por descargas de potenciais de fuso ou espículas agrupados ou isolados. Aspecto semelhante a êste sỏmente era observado em animais com lesões restritas ou pouco extensas da formação reticular quando se administravam doses muito maiores de pentobarbital (30 a $50 \mathrm{mg} / \mathrm{kg}$ ). A medida que novas doses iam sendo aplicadas, os períodos de silência elétrico cortical se tornavam mais longos e os potenciais espiculares mais escassos, menos amplos e mais lentos, até que desapareciam completamente (fig. 3). Este quadro final (inha isoelétrica) geralmente ocorria com doses de 20 a $30 \mathrm{mg} / \mathrm{kg}$ nos animais com lesão muito extensa e com 60 a $90 \mathrm{mg} / \mathrm{kg}$ naqueles com lesōes parciais da formaçāo reticular mesencefálica.

4. Nas preparações agudas de hemicérebro isolado as lesōes sempre eram extensas de maneira a destruir completamente uma das metades da formação reticular mesencefálica. Nestes animais, doses de 5 a $20 \mathrm{mg} / \mathrm{kg}$ de Nembutal, aplicadas intravenosamente, provocavam o aparecimento de fusos bem organizados no hemisfério cerebral contralateral à lesão. No hemisfério cerebral isolado, estas 
Fig. 3 - Efeito do Nembutal sôbre o ECoG de preparação aguda

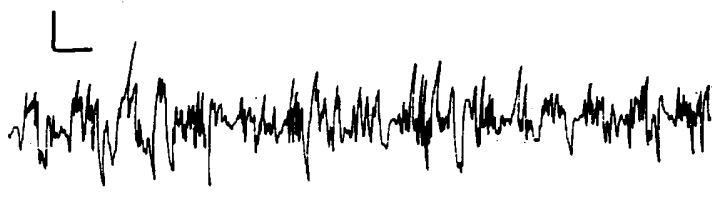
com lesão extensa da formacão reticular mesencefálica, atingindo também as porções ventrocaudais do diencéfalo. No traçado superior observa-se o ECoG antes da injeção do barbitúrico; no segundo traçado, após a injecão intravenosa de $10 \mathrm{mg} / \mathrm{kg}$ de Nembutal, surgem periodos de inatividade elétrica; no último traçado no-

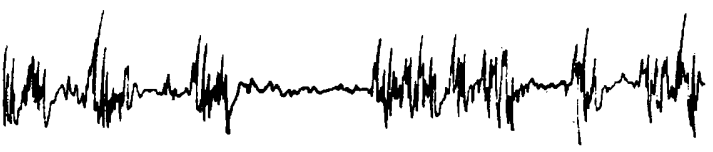
tam-se espículas de baixa voltagem e grandes períodos de silêncio elétrico, após a injeção de $20 \mathrm{mg} / \mathrm{kg}$ da droga. Calibração: $50 \mu \mathrm{V}$ e $1 \mathrm{~s}$.

mesmas doses determinavam precocemente desorganização dos fusos até então bem constituidos. Tais doses também provocavam, ocasionalmente, o aparecimento de espiculas, principalmente no hemisfério cerebral correspondente à lesão da formaçăo reticular (fig. 4).

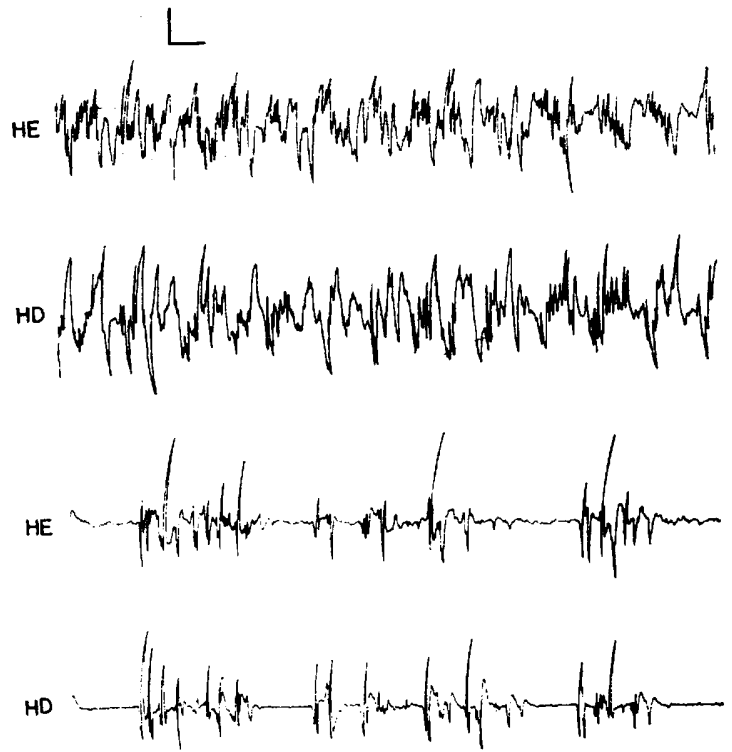

Fig. 4 - Efeito do Nembutal sôbre o ECoG de uma preparação aguda com lesão unilateral da formação reticular mesencefálica. A lesão foi feita à esquerda. Nos dois tracados superiores observa-se o ECoG antes da administraçāo do barbitúrico. Nos dois seguintes, após a injeção de $20 \mathrm{mg} / \mathrm{kg}$ da droga, nota-se nitidamente que houve desorganização dos fusos do hemisfério esquerdo, enquanto os do direito ainda se apresentam bem organizados. Calibração: $50 \mu \mathrm{V}$ e 18. 
5. Nos animais em preparação crônica, com lesão uni ou bilateral, o Nembutal foi aplicado intraperitonealmente nas doses de 20 a $100 \mathrm{mg} / \mathrm{kg}$. Comumente eram administradas doses de 20 a $40 \mathrm{mg} / \mathrm{kg}$ uma ou duas vêzes durante a evolução da preparação, reservando para a última sessão a aplicação de 50 ou $100 \mathrm{mg} / \mathrm{kg}$. Os efeitos da droga sôbre o ECoG variavam à medida que esta ia sendo absorvida. Depois de 3 a 5 minutos já se observava refôrço dos fusos, que se apresentavam mais puros e organizados. Nas preparaçōes de hemicérebro isolado os fusos se mostravam mais puros no hemisfério cerebral contralateral à lesão. Progressivamente os potenciais de fuso iam se tornando mais lentos e aos 10 ou 15 minutos as espículas predominavam no traçado. Quando as doses eram inferiores a $50 \mathrm{mg} / \mathrm{kg}$, em geral não se observava depressão da atividade elétrica cortical. Com doses de 50 a 100 $\mathrm{mg} / \mathrm{kg}$ surgiam períodos de inatividade após 15 a 20 minutos e as espículas se tornavam cada vez mais raras até desaparecerem totalmente, persistindo apenas uma linha isoelétrica.

6. Outro efeito muito nítido e geral do Nembutal sôbre o ECoG de animais com lesão uni ou bilateral da formação reticular mesencefálica foi o de tornar isócronos os potenciais dos dois hemisférios cerebrais. Este efeito fol observado tanto nas preparações agudas como nas crônicas. A isocronização geralmente só era notada com doses relativamente elevadas da droga. Tais drogas eram maiores nas prepa-

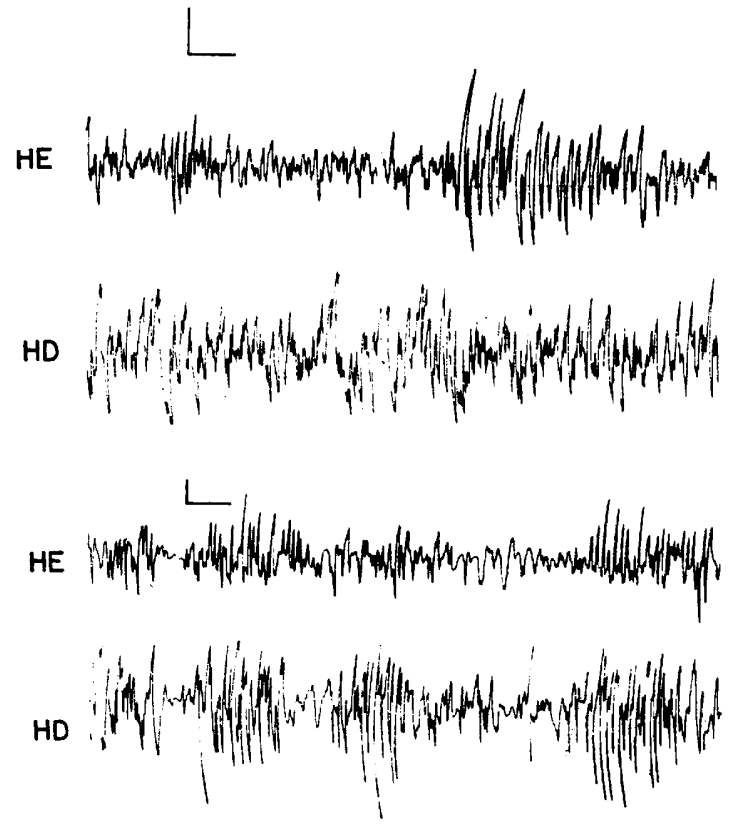

Fig. 5 - Efeito do Nembutal sôbre o ECoG de uma preparacão aguda com lesão bilateral extensa da formação reticular mesencefálica. Nos dois traçados superiores observa-se o ECoG de áreas cerebrais homólogas (área 2) antes da administração da droga. Nos dois traçados inferiores, após injeção de $20 \mathrm{mg} / \mathrm{kg}$ de Nembutal por via intravenosa, nota-se o aparecimento de ondas lentas e espiculas sincronas sôbre fundo isoelétrico. Calibração: $50 \mu \mathrm{V}$ e $1 \mathrm{~s}$. 
rações com lesão parcial ou pouco extensa (40 a $50 \mathrm{mg} / \mathrm{kg}$ ) e bem menores naquelas com lesões muito extensas (10 a $20 \mathrm{mg} / \mathrm{kg}$ ). A atividade de áreas corticais homólogas, que antes da administração do Nembutal era geralmente assincroma, tornava-se isócrona com a injeção de doses crescentes do barbitúrico (figs. 5 e 6 ).

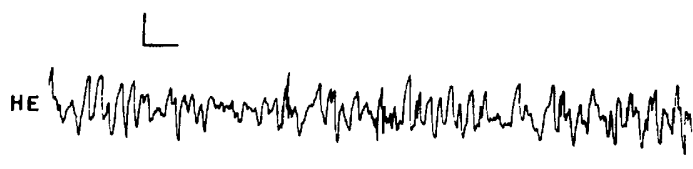

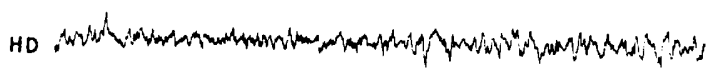

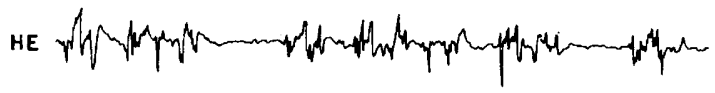

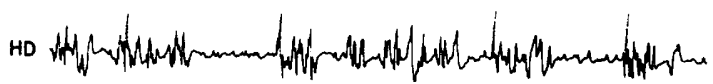

Fig. 6 - Efeito do Nembutal sôbre o ECoG de uma preparação aguda com lesão da metade esquerda da formacão reticular mesencefálica. Nos dois traçados superiores observa-se o ECoG de areas cerebrais homólogas (área 2) antes da administração da droga, notando-se assimetria evidente entre ambos. Nos dois traçados inferiores, após injecão de $40 \mathrm{mg} / \mathrm{kg}$ de $\mathrm{Nem}$ butal por via intravenosa, nota-se o aparecimento de ondas lentas e espiculas sincronas sôbre fundo isoelétrico. Calibração: $50 \mu \mathrm{V}$ e $1 s$.

Inicialmente se observam fusos sincrônicos; ulteriormente os potenciais dêstes fusos se tornavam mais lentos e surgiam periodos de ausencia de atividade elétrica cortical, interrompidos por descargas sincrônicas de espiculas nos hemisférios cerebrais.

\section{COM E N T A RIOS}

O efeito sincronizador do pentobarbital, observado mesmo em preparações com destruição completa da formação reticular mesencefálica, é outro fato indicativo da existência de mecanismos ativadores do ECoG situados rostralmente a ela ${ }^{12}$. Várias tentativas foram feitas no sentido de localizar a sede de ação dos barbitúricos. Keeser e Keeser ${ }^{8}$, aplicando barbitúrico marcado com cloreto férrico no coelho, encontraram a maior fixação dessa substância ao nível do tálamo e do corpo estriado. Tal verificação não foi, contudo, confirmada por outros autores, cabendo a French, Verzeano e Magoun ${ }^{4}$ provar experimentalmente que os barbitúricos bloqueiam a propagação de impulsos através da formação reticular mesencefálica. Atual- 
mente a maioria dos neurofisiologistas admite que os efeitos dos barbitúricos sôbre o ECoG e o comportamento se devem à ação exercida por estas drogas ao nivel da formação reticular. No entanto, o sono induzido pelos barbitúricos não é idêntico ao espontâneo, como primeiramente salientaram Brazier e Finezinger ${ }^{2}$. Por outro lado, Himwich e Rinaldi ${ }^{5}$ chamaram a atenção para o fato de que a ação dos barbitúricos sôbre o sistema nervoso central não pode ser explicada simplesmente pela depressão da formação reticular mesodiencefálica, devendo haver também um efeito especial ao nível do córtex cerebral. Segundo êstes autores, a ação destas substâncias se exerce progressivamente no sentido rostrocaudal, sendo mais acentuada sôbre o córtex cerebral e núcleo caudado e atingido menos o tálamo e o tronco cerebral. Soulairac, Cahn, Gottesmann e Alano ${ }^{14}$, estudando no rato e no coelho o efeito de barbitúricos e de outras drogas hipnógenas (derivados benzodiazepínicos e metaqualone), chegaram à conclusão de que tais drogas produzem sono por mecanismo inteiramente diverso, determinando manifestações eletrofisiológicas muito diferentes das observadas com os barbitúricos. De acôrdo com êstes autores, os barbitúricos deprimem intensamente as estruturas reticulares e em menor grau o córtex cerebral, ao passo que as outras drogas agem preponderantemente sôbre êste e o hipocampo.

Apesar de ser grande a variedade de substâncias hipnógenas, as modificações do ECoG encontradas em cada caso não são idênticas, como realçam Winters, Mori, Spooner e Bauer ${ }^{15}$; êste fato indica, provàvelmente, diversidade de mecanismos de ação para cada grupo de drogas. O éter, por exemplo, que segundo French, Verzeano e Magoun ${ }^{4}$ bloqueia a formação reticular mesencefálica, não causa o aparecimento de fusos no ECoG. Experiências em andamento (Pereira, Rocha e Timo-Iaria) demonstram que esta droga, além de não provocar a ocorrência de fusos corticais no rato intacto, determina sua abolição em preparações crônicas de cérebro isolado, inclusive com a injeção adicional de pequenas doses de pentobarbital. A atividade característica desta preparação é substituída inicialmente por ritmo rápido e de baixa voltagem e logo a seguir por ondas lentas amplas e ritmadas. Doses excessivas de éter induzem quadro eletrocorticográfico muito semelhante ao provocado por doses altas de pentobarbital, isto é, periodos longos de inatividade elétrica cortical interrompidos por surtos de ondas lentas e espículas síncronas nos dois hemisférios. Após a suspensão da inalação da droga seu efeito ainda se prolonga durante 20 a 30 minutos; sòmente depois dêsse lapso de tempo é que recomeçam a aparecer os fusos. Aparentemente, portanto, o éter não só bloqueia o sistema reticular ativador ao nivel do mesencéfalo, mas também inibe o sistema recrutador talâmico, considerado como responsável pelos fusos. As ondas lentas observadas no ECoG de animais anestesiados com éter poderiam ser, como demonstraram Naquet e col. ${ }^{10} \mathrm{em}$ gatos totalmente talamectomizados, de origem cortical, da mesma maneira que as espículas. Outra hipótese para explicar tal atividade é a de que essas ondas lentas seriam produzidas por um sistema talâmico independente do vinculado aos fusos, como postula Jasper ${ }^{7}$. O emprêgo do éter como anestésico em nossas preparações agudas talvez possa explicar o fato de haver retardamento de 10 a 20 minutos após as lesões reticulares para o aparecimento dos fusos. 
Saxena, Tangri e Bhargava ${ }^{13}$ verificaram, em preparaçōes agudas de cérebro isolado no gato, que a administração de tiopental sódico (tiobarbitúrico), tioridazina (neuroléptico) e clordiazepóxido (tranqüilizante menor) acentuavam a sincronização do ECoG, elevando a voltagem e diminuindo a frequência dos fusos. Por outro lado, as mesmas drogas provocavam queda do limiar para a obtenção de fusos e de respostas de recrutamento por estimulação do tálamo. Estes pesquisadores interpretaram seus resultados admitindo a existência de mecanismos sincronizadores e dessincronizadores nos níveis mais altos do sistema nervoso, considerando o núcleo caudado como parte importante de tais mecanismos. As drogas empregadas, ainda de acôrdo com Saxena e col., bloqueariam os componentes ativadores situados rostralmente ao mesencéfalo, aumentando a sincronização do ECoG nas preparações de cérebro isolado.

Os efeitos do pentobarbital observados em nossas preparações de cérebro isolado assemelham-se parcialmente aos descritos por Saxena e col.. Verificamos que doses pequenas de Nembutal (5 a $20 \mathrm{mg} / \mathrm{kg}$ ) aplicadas intravenosamente em preparações agudas com lesão bilateral da formação reticular mesencefálica, reforçam nìtidamente os fusos, tornando-os mais puros e aumentando sua periodicidade (fig. 2); nas preparações com lesão parcial êstes efeitos eram ainda mais evidente (fig. 1). Resultado similares foram observados em preparações crônicas com doses de 20 a $40 \mathrm{mg} / \mathrm{kg}$ injetadas no peritônio. No entanto, em preparações com destruição bilateral ma:s ampla da porção rostral do tronco encefálico, atingindo também a região ventrocaudal do diencéfalo, o efeito do Nembutal era inteiramente diverso. O ECoG dêstes animais, mesmo antes da injeção da droga, apresentava-se pobre em fusos, predominando amplamente as ondas lentas e com raras espiculas. A explicaçāo dêste quadro eletrocorticográfico pode, a nosso ver, estar vinculada à destruição parcial do sistema sincronizador talâmico ou à sua inibição funcional pela proximidade da lesão eletrolítica. Em tais casos, pequenas doses de Nembutal (5 a $30 \mathrm{mg} / \mathrm{kg}$ ), injetadas intravenosamente, determinavam depressão intensa e precoce do ECoG, o qual quase imediatamente se transformava em linha isoelétrica interrompida por surtos esporádicos de ondas lentas e de espículas isoladas ou agrupadas (figs. 3 e 5). Efeitos semelhantes, se bem que menos acentuados, eram observados com injeção das mesmas doses do barbitúrico em preparações agudas de hemicérebro isolado. Nestes casos, ao lado do aparecimento de fusos bem organizados no hemisfério cerebral contralateral à lesão, ocorria depressão ou desorganização dos fusos prèviamente registrados no hemisfério cerebral isolado, surgindo também espículas em alguns casos (fig. 4).

Quando aumentávamos as doses do Nembutal nas preparações com lesỏes parciais ou totais da formação reticular circunscritas ao mesencéfalo ocorria lentificação progressiva do ECoG, com queda da amplitude dos potenciais, até o desaparecimento quase total da atividade elétrica. Nesta fase ainda eram notados surtos esporádicos de ondas lentas e de espículas, isoladas ou agrupadas, sôbre o fundo isoelétrico, sendo estas, finalmente, também abolidas por doses adicionais de Nembutal. As doses do barbitúrico que 
levavam a êste quadro final variaram de 60 a $90 \mathrm{mg} / \mathrm{kg}$, injetadas intravenosamente, nas preparações agudas e de 50 a $100 \mathrm{mg} / \mathrm{kg}$, injetadas no peritônio, nas crônicas.

Outro efeito nítido do Nembutal, observado em tôdas as preparações, foi o de tornar isócrona a atividade elétrica dos dois hemisférios cerebrais. Doses relativamente elevadas da droga, que variavam de acôrdo com a extensão das lesões, determinavam a ocorrência simultânea de potenciais (fusos ou espículas) no ECoG dos dois hemisférios cerebrais (fig. 6).

De maneira geral os efeitos observados tanto nas preparações agudas como nas crônicas com lesão bilateral, parcial ou total, da formação reticular mesencefálica mostram-se muito semelhantes aos descritos por Negrão ${ }^{11}$ no rato intacto tratado com doses similares de Nembutal. Tal semelhança de efeitos indica que a destruição da referida formação é insuficiente para liberar completamente o mecanismo sincronizador talâmico da ação frenadora de sistemas antagônicos. O barbitúrico aplicado nesta preparação, como admitem Saxena e col. ${ }^{13}$, bloquearia os demais contingentes ativadores, possibilitando a sincronização máxima do ECoG.

Parece-nos, contudo, que a ação do pentobarbital não se restringe apenas à depressão dos sistemas ativadores do ECoG. Isto ocorre sòmente com doses relativamente pequenas da droga, pois à medida que estas se vão elevando nota-se também inibição do mecanismo sincronizador. De fato, com o aumento das doses de Nembutal os fusos desaparecem ràpidamente, sendo substituídos por ondas lentas e espículas esporádicas, que surgem sôbre um fundo isoelétrico. Erovável, portanto, que existam na realidade graus diferentes de sensibilidade ao pentobarbital, sendo as estruturas ativadoras deprimidas com doses menores que as sincronizadoras. Quando o mecanismo talâmico sincronizador é parcialmente destruido, ou funcionalmente inibido, por lesões mesodiencefálicas extensas, as doses necessárias de Nembutal para deprimí-lo são bem menores, o que vem reforçar nossa interpretação.

O córtex cerebral é, dentre as estruturas relacionadas com a atividade elétrica cortical, a que, aparentemente, apresenta maior resistência à ação do pentobarbital, pois a configuração eletrocorticográfica que persiste por mais tempo no traçado parece-nos ser de origem exclusivamente cortical. Vár:os pesquisadores, como Bremer ${ }^{3}$ e Ingvar ${ }^{6}$, observaram atividade rítmica no córtex cerebral completamente isolado. Este último fisiologista descreve ondas lentas e espículas, inclusive agrupadas, como comuns em tal preparação, sendo observados também períodos mais ou menos extensos de silêncio elétrico. Kristiansen e Courtosis ${ }^{9}$ constataram atividade cortical semelhante ao ritmo alfa após talamectomia total ou no córtex cerebral isolado de tôdas suas conexões corticais e subcorticais.

Em trabalho que estamos desenvolvendo atualmente (Pereira, Hoshino, Rocha e Timo-Iaria) temos observado que a destruição eletrolitica total de um dos tálamos no rato determina, no hemisfério cerebral correspondente, ECoG com ondas lentas e espículas mescladas com atividade dessincronizada. Nas fases iniciais ocorre depressão intensa da atividade elétrica cortical, que se manifesta como linha isoelétrica na qual despontam esporàdicamente 
potenciais espiculares de baixa voltagem. Aos poucos tais espículas vão-se tornando mais freqüentes e amplas, associando-se a ondas lentas, que ora predominam no traçado, ora são sobrepujadas pelas espiculas; a atividade dessincronizada torna-se evidente em fases mais tardias, tanto durante a vigília como na fase paradoxal do sono. Os fusos não reaparecem no traçado mesmo em preparações com 30 dias de seguimento. Naquet e col. ${ }^{10}$ descreveram, no gato totalmente talamectomizado, resultados em tudo semelhantes aos nossos. Doses adequadas de Nembutal administradas a ratos com destruição talâmica unilateral, provocam, no hemisfério cerebral correspondente à lesão, intensificação das espículas, que se tornam mais amplas e freqüentes, enquanto no oposto surgem fusos típicos. Doses maiores da droga, contudo, determinam progressiva rarefação das espiculas, que passam a ocorrer simultâneamente nos dois hemisférios cerebrais. E interessante assinalar que tal sincronia é também verificada após injeção de Nembutal, em preparações agudas com destruição talâmica bilateral, o que indica ser ela independente do tálamo.

Os fatos discutidos podem significar que o pentobarbital atua sôbre o córtex cerebral de dupla forma: em determinadas doses provoca irritação cortical, causando o aparecimento de espículas de grande voltagem (muito semelhantes às descargas conseqüentes à aplicação tópica de estricnina sôbre o córtex cerebral); em doses maiores acaba por deprimi-lo, bloqueando por completo a sua atividade elétrica. A isocronia dos potenciais registrados nos dois hemisféricos cerebrais após a injeção de doses relativamente altas de Nembutal é de difícil explicação mas, òbviamente, independe do tálamo, uma vez que sua destruição total não a impede. É possível que a sincronização dos potenciais, mesmo na ausência do tálamo, seja feita através das conexōes intra e inter-hemisféricas, por fibras de associação e comissurais, que ligam porções distantes do mesmo ou de ambos os hemisféricos cerebrais, respectivamente. A propósito desta possibilidade devemos lembrar a afirmativa de Ajmone-Marsan" ${ }^{1}$ de que "não é absurdo supor que, em determinadas condiçőes, qualquer região cortical ou subcortical possa assumir temporàriamente o papel de marca-passo para outras áreas ou, mesmo, para todo o córtex cerebral". A depressão da atividade elétrica, observada logo após a destruição total do tálamo,pode traduzir um estado de choque dos neurônios do córtex cerebral, provocado pela súbita interrupção de suas conexões com o tálamo e grande parte do neureixo. Ulteriormente, a desaferentação cortical poderia determinar, pelo contrário, um estado de hipersensibilidade de seus neurônios, que passariam a reagir intensamente tanto a estímulos fisiológicos como farmacológicos.

\section{R E S U M O}

Para êste estudo foram empregados 35 ratos da raça Wistar em preparação aguda (24 com lesão bilateral e 11 com lesão unilateral) da formação reticular mesencefálica e 18 preparações crônicas. O método empregado na obtenção das preparações foi descrito em trabalho anterior ${ }^{12}$. $O$ objetivo desta série de experiências foi o de verificar de que maneira o pentobarbital interfere sôbre as caracteristicas da atividade elétrica cortical após lesão da 
formação reticular mesencefálica. Para tal, em animais preparados agudamente, foram feitas lesões progressivamente mais extensas e o barbitúrico injetado por via intravenosa em doses crescentes. A fim de testar a integridade do sistema reticular ativador ascendente, além de estímulos dolorosos intensos, aplicávamos pulsos de 5 a $10 \mathrm{~V}, 100 \mathrm{~Hz}$, e $0,1 \mathrm{~ms}$ à formação reticular mesencefálica situada abaixo da região lesada. $\mathrm{A}$ ausência de reação de alerta cortical (dessincronização) nos assegurava que tal sistema havia sido lesado completamente. Nas preparações crônicas o pentobarbital era injetado por via intraperitoneal. Dessas experiências concluimos o seguinte: 1. Aumento da sincronização do eletrocorticograma nos animais com lesões parciais ou totais da formação reticular mesencefálica. 2. Depressão acentuada e precoce da atividade eletrica cerebral nos ratos com lesão muito extensa (comprometendo também a porção ventrobasal do tálamo). 3. Isocronismo da atividade elétrica cortical nos dois hemisférios cerebrais. 4. O pentobarbital parece agir tanto sôbre os sistemas ativadores como sôbre o sincronizador do eletrocorticograma. As doses pequenas deprimem os primeiros, liberando o segundo, enquanto que as maiores bloqueiam também êste último. Sòmente doses muito mais altas é que fazem desaparecer totalmente a atividade do córtex cerebral, que se mostra, portanto, mais resistente à ação da droga.

\section{S U M M A R Y}

Action of sodium pentobarbital on the cortical electrical activity of the rat after lesion of the midbrain reticular formation

This study was performed on 35 albino rats prepared for acut and 18 for chronic experiments. The midbrain reticular formation was electrolytically destroyed on both sides in 24 animals, and in 11 on one side. The interruption of the reticular activating system was checked by strong nociceptive and electrical stimulation below the lesioned area. In acute preparations pentobarbital was given by intravenous injection in increasing doses, and in chronic experiments by intraperitoneal injections.

The barbiturate always augmented synchronization of the electrocorticogram but induced an early depression of the electrical activity in rats with bilateral extensive lesions. After barbiturate administration the electrocorticogram of both hemispheres tended to became more isochronized. Pentobarbital seems to depress the activating systems in small doses, thus liberating the synchronizing systems, whereas larger doses block also the latter. Only very large doses depress the cortical activity.

1. AJMONE-MARSAN, C. - The thalamus: data on its functional anatomy and some aspects of thalamo-cortical integration. Arch. ital. Biol. 103:847, 1965.

2. BRAZIER, M. A. B. \& FINESINGER, J. E. - Action of barbiturates on the cerebral cortex: electroencephalographic studies. Arch. Neurol. Psychiat. (Chicago) 53:51, 1945.

3. BREMER, F. - Considérations sur l'origine et la nature des "ondes» cérébrales. Electroenceph. clin. Neurophysiol. 1:177, 1949. 
4. FRENCH, J. D.; VERZEANO, M. \& MAGOUN, H. W. - A neural basis for the anesthetic state. Arch. Neurol. Psychiat. (Chicago) 69:519, 1953.

5. HIMWICH, H. E. \& RINALDI, F. - A comparison of effects os reserpine and some barbiturates on the electrical activity of cortical and subcortical strutures of brain of rabbits. Ann. N. Y. Acad. Sci. 61:27, 1955.

6. INGVAR, D. H. - Electrical activity of isolated cortex in the unanesthetized cat with intact brain stem. Acta physiol. scand. 33:169, 1955.

7. JASPER, H. H. - Diffuse projection stystems: the intregative action of the thalamic reticular system. Electroenceph. clin. Neurophysiol. 1:405, 1949.

8. KEESER, E. \& KEESER, J. - Uber die Lokalisation des Veronals der Phenylaethyl und Diallylbarbitursäure in Gehirn. Arch. exp. Pathol. Pharmak. 125: 251,1927 .

9. KRISTIANSEN, \& COURTOIS, G. - Rhythmic electrical activity from isolated cerebral cortex. Electroenceph. clin. Neurophysiol. 1:265, 1949.

10. NAQUET, R.; DENAVIT, M.; LANOIR, J. \& ALBE-FESSARD, D. - Altérations transitoires ou définitives des zones diencéphaliques chez le chat: leurs effects sur l'activité électrique cortícale et le sommeil. In $\mathbf{M}$. Jouvet. Neurophysiologie des Etats de Sommeil. Centre National de la Recherche Scientifique, Paris, 1965 , pg. 107.

11. NEGRAO, N. - Ciclos de sono, fusos de sono natural e anestésico e potenciais de recrutamento no rato. Tese. Faculdade de Medicina da Universidade de Săo Paulo, 1967.

12. PEREIRA, W. C.; ROCHA, T. L. \& TIMO-IARIA, C. - Atividade elétrica cerebral do rato com lesões da formação reticular mesencefálica. Arq. Neuro-psiquiat. (São Paulo) 28:185, 1970.

13. SAXENA, P. N.; TANGRI, K. K. \& BHARGAVA, K. P. - An experimental study of the synchronizing system in the brain. Electroenceph. clin. Neurophysiol. $17: 506,1964$

14. SOULAIRAC, A.; CAHN, J.; GOTTESMANN, C. \& ALANO, J. - Neuropharmacological aspects of the action of hypnogenic substances on the nervous system. In K. Akert, C. Bally and J. P. Schadé: Sleep Mechanisms, Amsterdam, 1965, pg. 194.

15. WINTERS, W. D.; MORI, K.; SPOONER, C. E. \& BAUER, R. O. - The neurophysiology of anesthesia. Anesthesiology 28:65, 1967.

Clínica Neurológica - Faculdade de Medicina da Universidade de São Paulo Caixa Postal 3461 - São Paulo, SP — Brasil. 